\title{
Viewpoints on Healthcare Delivery Science Education Among Practicing Physicians in a Rural State
}

This article was published in the following Dove Press journal:

Advances in Medical Education and Practice

\author{
Kristin Weeks $\mathbb{D}^{1,2}$ \\ Morgan Swanson (iD ${ }^{1,2}$ \\ Amanda Manorot ${ }^{3}$ \\ Gabriel Conley ${ }^{4,5}$ \\ Joseph Nellis ${ }^{6}$ \\ Mary Charlton ${ }^{2}$ \\ Alan Reed (iD)
}

'Medical Scientist Training Program, Carver College of Medicine, University of lowa, lowa City, IA, USA; ${ }^{2}$ Department of Epidemiology, College of Public Health, University of lowa, lowa City, IA, USA;

${ }^{3}$ Department of Obstetrics and

Gynecology, University of Michigan, Ann Arbor, MI, USA; ${ }^{4}$ Medical Training

Program, Carver College of Medicine, University of lowa, lowa City, IA, USA;

${ }^{5}$ Department of Business, Tippie College of Business, University of lowa, lowa City, IA, USA; ${ }^{6}$ Department of Surgery, Duke University, Durham, NC, USA;

${ }^{7}$ Department of Surgery, University of lowa Hospitals and Clinics, lowa City, IA, USA
Correspondence: Alan Reed

Department of Surgery, University of lowa Hospitals and Clinics, SE $427 \mathrm{GH}$, 200 Hawkins Drive, lowa City, IA 52242 USA

Tel + I 319-356-0537

Email alan-reed@uiowa.edu
Introduction: Healthcare Delivery Science Education (HDSE) covers important aspects of the business of medicine, including, operations management, managerial accounting, entrepreneurship, finance, marketing, negotiations, e-health and policy/advocacy. We need to investigate and understand practicing physicians' viewpoints on HDSE in order to inform interventions capable of preventing the double loss phenomena and improving medical and continuing medical education opportunities in HDSE. This qualitative study aims to provide a rich, contextualized understanding of the HDSE experiences and interests of physicians practicing in a rural state through the intensive study of particular cases.

Materials and Methods: We interviewed 18 practicing physicians from a rural, Midwestern state over the telephone about their viewpoints on past experiences obtaining HDSE, interest in HDSE, barriers to pursuing HDSE, and interest in an example HDSE certificate program.

Results: Salient themes in our study were that physicians were interested in HDSE and believed HDSE could lead to improved patient care and practice efficiency. However, many of the respondents had not received longitudinal, diversified, didactic or practical HDSE. Time limited many physicians from pursuing HDSE opportunities. Many physicians in the study were interested in the example HDSE certificate program.

Discussion and Conclusions: Physicians in our qualitative study were interested in obtaining HDSE and had not received diversified, didactic HDSE in the past. Our research suggests innovative HDSE programs will likely be utilized and pursued if they are developed.

Keywords: healthcare delivery science, rural, management, continuing medical education, healthcare leadership

\section{Introduction}

The United States' healthcare industry has grown exceedingly complex over the last 20 years. Some reimbursement is transitioning from fee-for-service to value-based models with associated risk. ${ }^{1-3}$ Moreover, technologies and governmental policies continue to rapidly evolve. ${ }^{1-3}$ Even as these changes are being implemented, the cost of healthcare in the United States continues to rise reaching \$3.5 trillion in 2017 and amounting to $17.9 \%$ of the Gross Domestic Product. ${ }^{4-6}$

Due to their unique clinical viewpoints, physicians across all specialties are being called upon to assume wide-ranging formal and informal leadership and management roles in healthcare. In this variety of roles, they are faced with addressing a diverse set of priorities, from adapting to fee-for-service models, implementing technologies and 
policies, to improving medical outcomes and maintaining patient satisfaction. ${ }^{3,7}$ These leadership roles can range from managing a practice or committee, conducting a quality improvement project, restructuring their data management, to running an entire hospital system. The successful integration of physicians into leadership positions of all kinds has been demonstrated previously. For example, many hospitals with the highest quality scores have physician leaders. ${ }^{8}$ Likewise, hospital systems with physicians in management roles have been shown to have high management performance, operational effectiveness, and clinical quality. ${ }^{9-12}$

However, as physicians seek to assume leadership positions in healthcare, many are limited by financial resources, a lack of training, and time. ${ }^{3,7}$ A lack of training for leadership and management positions can result in a "double loss" phenomenon, or the loss of the physician's clinical skilledtime when they devote more time to leadership, as well as the loss of expert healthcare leadership, if the physician lacks training and consummate skillsets. ${ }^{3}$ The lack of leadership training among practicing physicians might be due to limited exposure to formal healthcare delivery science education (HDSE) in medical school and continuing medical education (CME). ${ }^{8,9,11,13,14}$ HDSE covers important aspects of the business of medicine, including, operations management, managerial accounting, entrepreneurship, finance, marketing, negotiations, e-health and policy/advocacy. HDSE practicably helps physicians who are called upon to take on either formal or informal leadership roles. ${ }^{15-18}$

There is a lack of data in the literature evaluating practicing physicians' experiences with and interest in HDSE. We need to investigate and understand practicing physicians' viewpoints on HDSE in order to inform interventions capable of preventing the double loss phenomena when physicians take on formal or informal leadership roles, improve medical and continuing medical education opportunities in HDSE, and enhance physician success in leadership roles and the quality of healthcare delivery. It is particularly pressing to understand the viewpoints of practicing physicians working in a rural state where a growing health professional shortage complicates efforts to provide effective healthcare and illuminates disparities in practicing physicians' HDSE. An improved understanding of these physicians' viewpoints on HDSE will allow for the development of important tools, educational interventions, and systemic changes to help these physicians successfully address important issues in their state, including access and management obstacles. ${ }^{19,20}$

Through our qualitative research, we aimed to explore a rich, contextualized understanding of the HDSE experiences and interests of physicians practicing in a rural state through the intensive study of cases. ${ }^{21}$ In this qualitative study, practicing physicians in a rural state were interviewed about their past experiences with HDSE, current attitudes toward HDSE, interest in a limited model HDSE certificate program, and barriers to pursuing HDSE.

\section{Methods}

\section{Instrument Creation}

We created a structured interview guide to be used in telephone interviews that included both open- and closed-ended questions. The interview guide was goal-driven toward investigating our research question and was informed by a review of the literature as well as Roger's Diffusion of Innovation Theory framework. The interview guide was pilot-tested and re-evaluated after initial interviews; no changes were made to the guide over the course of the study. The interview guide was structured to ask physicians about their specialty, years in practice, practice environment and the four areas of investigation, which included physicians' past HDSE experiences, interest in future HDSE, barriers to HDSE, and viewpoints on a limited model certificate program (detailed verbatim in Box 1).

Box I Description of Our Healthcare Delivery Science Education Certificate Program for Practicing Physicians

\begin{abstract}
A medical school has a healthcare delivery science education track that serves as an extra course of study for medical students. Students have four four-hour lectures per year taught by experts in the field. Topics of advocacy, e-health, legal issues, policy, business, financial accounting, marketing, public health, data management, innovation \& entrepreneurship, negotiations, and strategy are not repeated for three years. Students have access to an online classroom with prelecture and lecture materials. Outside of the classroom sessions, students complete a capstone research project on a topic of their choice, which is a substantial research or service project completed with mentors, practicing physicians and content experts. The capstone projects have taken the form of funding a free medical clinic, doing a cost effectiveness analysis on a surgical product, developing legislative or advocacy materials, etc.

This track creates a certificate program for practicing physicians lasting three years. You can join this certificate program as a practicing physician and attend lectures virtually, have access to the online classroom, and serve as a mentor or collaborator on capstone research or service projects that most interest you. If there is a project you have in mind, you could invite medical students to use this idea for their capstone project, with you as their mentor and collaborator.
\end{abstract}

Note: 1 . This box is the verbatim description that was read to the physicians during their telephone interviews. 


\section{Theoretical Framework}

We applied Rogers' Diffusion of Innovation Theory framework toward designing the description of the limited model certificate program and soliciting respondents' reactions to it. ${ }^{22,23}$ The Diffusion of Innovation Theory posits that people are more likely to adopt an innovation when the innovation is seen to have a relative advantage, compatibility, overcomes complexity, trialability, and observability. ${ }^{23}$ The example certificate program that was described to physician interviewees had a didactic and project component and was structured similarly to the program used for a medical student elective at our college. Our goal in including a project component was to provide participants with a real-life example of how to use learned information in a clinical setting to achieve tangible results. To reduce complexity in our certificate description, we did not discuss specific logistics of the hypothetical online platform nor additional requirements or grading schemes. Rather, we presented a straightforward certificate program requiring a relatively minimal time commitment (4 sessions per year, 4 hours per session) with the goal of providing physicians the basic fundamentals of HDSE (as opposed to a mastery level one might encounter in a degree bearing program) delivered in a virtual format for their convenience. We also asked physician participants to define their ideal time frame and level of commitment to reduce any subconscious barriers to trialability. After the analysis was completed, we applied the Diffusion of Innovation Theory five-component framework to summarize participants' reactions to this particular example certificate learning option.

\section{Participant Recruitment and Enrollment}

We aimed to enroll an equal number of family medicine physicians and non-family medicine physicians to ensure we were able to observe differences, if they existed, between primary care providers and specialists. We were particularly interested in these two groups because it is likely they differ in practice structure (private practice versus hospital based), and their perceived needs and motivations for pursuing HDSE might differ as well. Participants were eligible if they were practicing, licensed physicians in Iowa in 2018 and 2019. Licensing was confirmed through the Iowa Board of Medical Examiners.

Two sampling and recruiting strategies were used. Family medicine physicians were sampled from the only family medicine research network in our state, which is composed of 310 family medicine physicians in 75 of our state's 99 counties. The staff of the research network faxed recruitment letters to a random sample of 40 family medicine physicians after excluding the members in their network already participating as subjects in other research studies. Fax (versus email or telephone) is the only method used for communication by the research network. Nonfamily medicine physicians were recruited by maximum variation sampling across diverse hospital systems in our state and medical specialties. Two research teams at our institution emailed recruitment letters to the work email addresses of 12 non-family medicine physicians. Faxes were sent in batches of 20 and emails were sent in batches of six starting in January 2019.

Non-responders were re-contacted two additional times through fax (family medicine) and email (non-family medicine) within 2 weeks of each prior correspondence. In each correspondence, physicians were provided an informational invitation letter for the study, elements needed for informed consent, and a form to fill out that indicated their willingness to participate and three times/days that worked best for interviews.

We aimed to recruit physicians until we determined that saturation was achieved in each stratum, or when no additional themes were found. ${ }^{24}$ We achieved saturation after 40 family medicine and 12 non-family medicine physicians had been recruited (Figure 1).

\section{Data Collection}

One trained graduate research assistant (KW, Bachelor of Science, female, doctoral student with qualitative graduate experience) scheduled and conducted all interviews. Interviews were all formally scheduled by email and conducted over the telephone at the primary time/date preference that was provided by each physician. Participants were not familiar with the interviewer before the research encounter and learned that she was a student during interviews; they did not know her degree program, educational goals or other characteristics. Prior to each interview, participants provided informed consent, including the publication of anonymized responses. The consent process was approved by the IRB (\#201901815) of the University of Iowa.

All interviews were conducted by telephone using a structured interview guide and were audio-recorded. Probing questions were used to clarify response options and illicit additional explanation. Further, participants were asked to reflect, add additional comments, and clarify any of their responses at the end of each interview. 


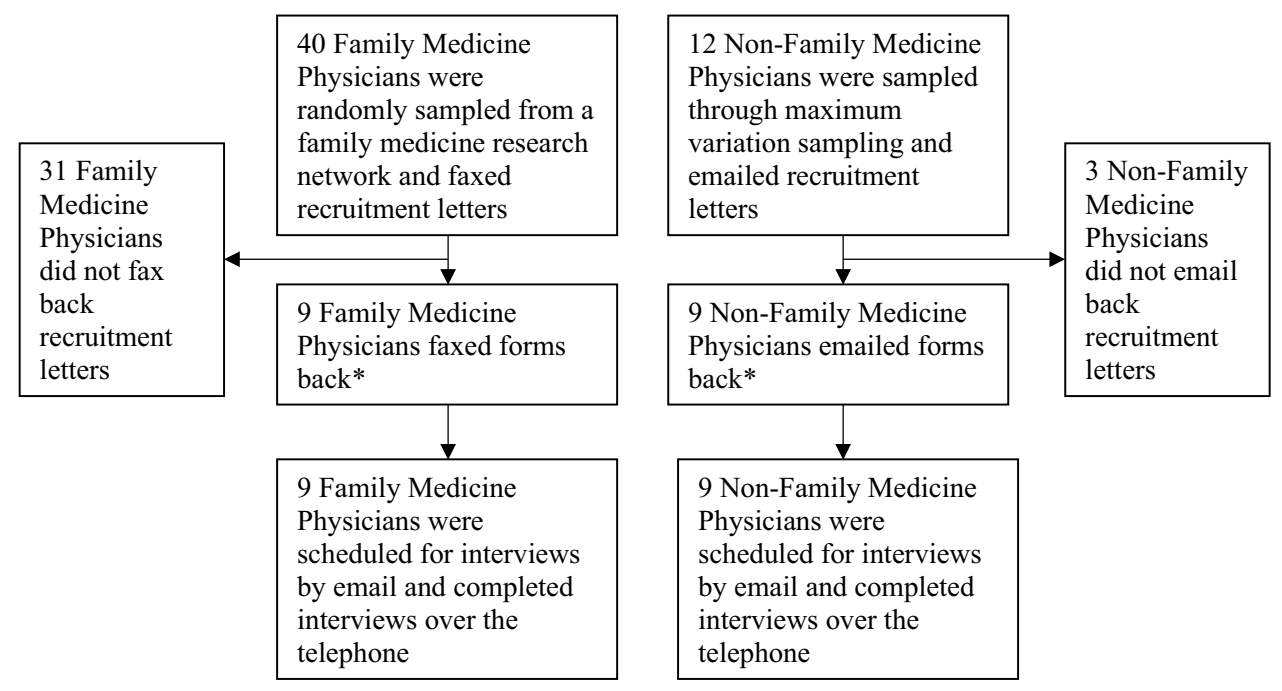

Figure I Recruitment strategy

Notes: This figure provides a description of the recruitment strategy and study population that was enrolled. *Forms indicated a willingness to participate and three times/ days that the physicians were available for interviews.

Participants were not re-contacted after the initial interview. The interviews lasted an average of 15 minutes. For all interviews, HDSE was defined as

The business of medicine, including, operations management, managerial accounting, entrepreneurship, finance, marketing, negotiations, e-health and policy/advocacy.

Participants were mailed twenty dollars as compensation following their interview. The last interview was conducted in April 2019.

\section{Data Analysis}

Telephone interviews were transcribed verbatim and reviewed for accuracy. Participants were not asked to review transcripts, nor to provide feedback about findings. Member checking was not conducted due to appropriate probing during interviews, invited reflection following interviews, active monitoring for consistency between responses during interviews, and concern about physicians' time limitations.

Two independent reviewers (KW and MBS) evaluated all interview transcripts and assigned themes to the four areas being investigated. ${ }^{25}$ Disagreements between independent reviewers were noted, and discrepancies were addressed through collaborative discourse until a mutual agreement was reached. ${ }^{5}$ Deviant cases were analyzed and discussed following the subset of a grounded theory known as constant comparison. ${ }^{26}$ The themes generated for each area of investigation and the relative salience of themes were compared between the family medicine versus non-family medicine physician stratum. Due to the lack of difference between these groups, results were presented for the physician cohort overall.

\section{Description of Study Participants}

Eighteen physicians, nine family medicine physicians (23\% participation rate) and nine non-family medicine physicians ( $75 \%$ participation rate) participated in our qualitative interview study (Image 2). Non-family medicine physicians were trained in pediatrics (2), internal medicine (2), surgical subspecialties (3), and psychiatry (1). Respondents practiced at both hospital and group practices worked for both publicly and privately owned systems, and were spread across a diverse set of healthcare systems in our state. Some held leadership positions, including one physician who was the head of a committee. Some were involved in the management of their own practices/departments and some had no formal or informal leadership roles at all. Most respondents were male. Two-thirds reported practicing in urban or suburban locations, and one-third reported practicing in a rural area (Table 1). Half had been practicing for less than 20 years.

\section{Results}

Within our four areas of investigation (past experiences, current interest, barriers, and interest in a certificate program), we identified 14 subthemes, or 2-5 subthemes for each area of investigation (Table 2). 
Table I Participant Demographics

\begin{tabular}{|l|l|l|}
\hline Characteristics & N & (\%) \\
\hline Male & 13 & 72 \\
\hline Female & 5 & 28 \\
\hline Rural* & 6 & 33 \\
\hline Suburban and urban* & 12 & 66 \\
\hline Practicing $\geq 20$ years & 9 & 50 \\
\hline Practicing <20 years & 9 & 50 \\
\hline
\end{tabular}

Note: *Providers self-identified as practicing in rural, suburban, or urban locations. Rurality options were not defined.

\section{Past HDSE Experiences}

Most practicing physicians stated that HDSE was not a significant part of their medical education or their continuing education. A salient theme among practicing physicians was that they had not received structured didactic HDSE after residency through their place of employment. The physicians that had received unstructured HDSE at their place of employment had done so through on-the-jobtraining. On-the-job-training was described as topicspecific education, such as medical billing, leadership, or financial responsibility. On-the-job-training occurred alongside new non-clinical obligations. For example, physicians received on-the-job-training as a new member of a special committee or when newly assuming an administrative role. Another salient theme among practicing physicians was that they had single-subject opportunities in HDSE, such as conference lectures and lectures through their respective national organizations. These singlesubject opportunities were only completed when specifically sought out by practicing physicians based on their own interests and initiatives. Finally, a salient theme among practicing physicians was that they lacked formal education on HDSE topics both during training and after completing residency. Some physicians mentioned they were optimistic that the amount of HDSE discussed in medical training and on-the-job training was slowly improving with time.

\section{Current Interest in HDSE}

Many practicing physicians were interested in obtaining HDSE, especially when delivered in a platform specific to their profession, practice type, and specialty. Interested participants thought HDSE would be valuable to them and, by extension, their patients. A growing dissatisfaction with the state of healthcare and a current inability to change the parts of their practice operations or their healthcare system they disliked seemed paramount to practicing physicians' interest. Correcting inefficiencies, improving care delivery, and having a voice in how physicians are managed motivated providers' interest in HDSE. Another salient theme among physicians was the desire to be able to improve their advocacy and policy literacy in order to optimize outcomes for their patient population, such as by actively supporting mental health funding reform. Commonly reported HDSE topics of interest were data management, policy and advocacy, public health, business management (operations), and financial management.

Disinterest in HDSE at the time of the interview was typically attributed to later career stage and competing goals and priorities, rather than a lack of interest in the topics. For example, some expressed they anticipated a decreased future interest because they were too advanced in their careers. Others were completely committed to seeing patients and did not want to detract any time away from patient care. Some physicians noted certain topics in HDSE did not interest them, but no one stated they were well informed on multiple HDSE topics or uninterested in every topic.

\section{Barriers to HDSE}

The overwhelming barrier to obtaining HDSE was time. Practicing physicians indicated many sources of time constraints, including family obligations, clinical duties, research efforts, email burdens and note writing. Physicians felt they were working at their limit most of the time. However, they still believed they could make time for HDSE if it were delivered in a flexible manner that required a modest time commitment. Other barriers were the cost of existing programs, cost of traveling to conferences, and a lack of programs targeted to physicians. Physicians also discussed life events that may make certain timeframes more optimal for HDSE than others, such as when their children left for college or when they did not have visiting trainees.

\section{Interest in a Certificate Program}

Most physicians were interested in the example certificate program that was presented to them. Physicians perceived the certificate program to have a relative advantage, compatibility, reduced complexity, trialability, and observability (Table 3 ). The main drivers for interest in the certificate 
Table 2 Themes of Practicing Physicians' Viewpoints on Healthcare Delivery Science Education

\begin{tabular}{|c|c|}
\hline Themes & Illustrative Quotes \\
\hline \multicolumn{2}{|l|}{ Past HDSE experiences } \\
\hline On the job experience & $\begin{array}{l}\text { "I would say not much (HDSE education). From a financial standpoint, obviously, coding and } \\
\text { billing is essentially making notes and billing for them." }\end{array}$ \\
\hline Single-subject independent pursuits & $\begin{array}{l}\text { "I have advocacy education experience. That's about it .... I've done it both through the } \\
\text { American Academy of Pediatrics, and a conference on it." }\end{array}$ \\
\hline No prior experience & $\begin{array}{l}\text { "Oh I didn't have any formal education in any of that. That's just something you know, back in } \\
\text { the day when I started, you just did it." } \\
\text { "Yeah, I would say no to that. We had minimal business aspects in the residency, all of which } \\
\text { I have long since forgotten." }\end{array}$ \\
\hline \multicolumn{2}{|l|}{ Current interest in HDSE } \\
\hline $\begin{array}{l}\text { It's important for young physicians, less for older } \\
\text { physicians }\end{array}$ & $\begin{array}{l}\text { "Personally, I'm not (interested in HDSE now), but I really see the importance of that. Other } \\
\text { younger physicians need to be educated in that." } \\
\text { "Well, I am (interested in HDSE), but l'm getting pretty old now. I'm probably going to retire in } \\
\text { the next year or two." } \\
\text { "I think it's really important for new physicians or medical students to get that because the } \\
\text { complexity of how healthcare is delivered really requires that." }\end{array}$ \\
\hline Patient care is a competing interest & $\begin{array}{l}\text { "I now have joined a group hospital based or hospital owned. So my involvement in the running } \\
\text { of the practice is not there." } \\
\text { "I was heavily involved in that sort of stuff, and l've made a move just to practice." } \\
\text { "Well, I've been roped into being a leader of various things, but I would much rather be sort of } \\
\text { focused on very detailed, clinical work than big picture work." }\end{array}$ \\
\hline $\begin{array}{l}\text { Interested in improving healthcare system or } \\
\text { practice }\end{array}$ & $\begin{array}{l}\text { "I'd say I am quite a bit interested. Well, I think a large part of it is that the system as it works } \\
\text { now is not always terribly efficient, and I think sometimes our goals are a little misdirected, and } \\
\text { I think that by understanding the delivery science, l'd be better able to advocate and try to } \\
\text { modify my own practice so that it would be more effective." } \\
\text { "I think that physicians need to have a voice in how medicine is being managed, and going } \\
\text { forward in the future I think physicians need to be more a part of that" }\end{array}$ \\
\hline $\begin{array}{l}\text { Interested in advocating and changing policy on } \\
\text { behalf of patients }\end{array}$ & $\begin{array}{l}\text { "I'm always interested in advocacy education. I think part of a pediatrician's job is advocacy." } \\
\text { "I'm interested in the care delivery and disparities in care. And so I think that that sort of } \\
\text { knowledge would be helpful for me in understanding what's going on with that. And in making } \\
\text { changes." } \\
\text { "As I age and grow in my profession, I'm realizing that there's a lot that we're doing that is not } \\
\text { helping the country as a whole, I don't know how to change that." }\end{array}$ \\
\hline $\begin{array}{l}\text { Interest is contingent on HDSE being focused on } \\
\text { specialty and practice type }\end{array}$ & $\begin{array}{l}\text { "You could say moderate because I guess I would be interested in terms of how it affects my } \\
\text { surgical practice" } \\
\text { "Even though I am hospital employed and academic, we are expected to be very aware of the } \\
\text { financial compensation and how that works. And so, training in that would be valuable." }\end{array}$ \\
\hline \multicolumn{2}{|l|}{ Barriers to HDSE } \\
\hline Time & $\begin{array}{l}\text { "Time constraints I guess, and taking time away from seeing patients, I think is the biggest } \\
\text { thing." } \\
\text { "Time. Time's probably the biggest one. As a family physician who works full time, I probably } \\
\text { work about } 60 \text { hours, which includes my paperwork time, which is a big chunk of that. So, it's } \\
\text { just finding time to fit it in, basically." }\end{array}$ \\
\hline
\end{tabular}

(Continued) 
Table 2 (Continued).

\begin{tabular}{|c|c|}
\hline Themes & Illustrative Quotes \\
\hline Cost of the Programs & $\begin{array}{l}\text { "Financial I guess, too, right? Anytime, if you're gonna travel to one of these courses in a fee for } \\
\text { service model, or eat what you kill, you lose money" }\end{array}$ \\
\hline \multicolumn{2}{|l|}{ Interest in the certificate program } \\
\hline Interest driven by desire to mentor & $\begin{array}{l}\text { "My philosophy now in this part of my career, of wanting to make sure that those that follow } \\
\text { behind me have experience and the expertise to do the things that will really make, I think, } \\
\text { their practice much more enjoyable, as well as improving practice now, policies now and in the } \\
\text { future." } \\
\text { "Well, I think through mentoring students, it would force me to focus what l'm learning, so to } \\
\text { go through some of the materials and to read more about the topics. I think that's what I enjoy, } \\
\text { sort of having that interaction with the students." }\end{array}$ \\
\hline Interest driven by HDSE & $\begin{array}{l}\text { "But I think, if you have a better understanding of like what's going on in the background I just } \\
\text { think that you have just a better understanding of why some of the decisions that are made and } \\
\text { it just makes a lot more sense and you don't get as emotional about those things. Like when } \\
\text { someone is telling you you have to do something different but you don't really understand why, } \\
\text { that can be upsetting." }\end{array}$ \\
\hline $\begin{array}{l}\text { Interest driven by desire to work with } \\
\text { likeminded people }\end{array}$ & $\begin{array}{l}\text { "I guess, another big reason is forming that network. There's a great networking opportunity } \\
\text { for experienced physicians who have started their own practice or innovated a new } \\
\text { technology, as well as the students." } \\
\text { "It is the classes, but being able to develop an idea on my own or with others where I work, to } \\
\text { do it in that structured setting where you have people who can give you feedback and to help } \\
\text { you develop your ideas. So that's part of the networking, but it's more than that. It's also having } \\
\text { a support group, a peer group." }\end{array}$ \\
\hline
\end{tabular}

were the subject matter, mentoring, and networking opportunities. Most saw professional advancement and leadership value in the didactic, expert-led lectures; however, some stated they were just curious to learn about HDSE from an intellectual standpoint. Practicing physicians also saw personal value in sharing their experiences with students. Some stated they felt a responsibility to their profession to help medical students. Finally, practicing physicians were interested in pursuing an HDSE certificate program for the purposes of forming relationships, such as connecting with new like-minded people. Some thought they could use their gained knowledge to build momentum in the workplace, solve an existing problem, and/or strengthen culture.

\section{Discussion}

Many of the physicians in our study were interested in HDSE and expressed the belief that HDSE could lead to improved patient care and practice efficiency. However, many of the respondents had not received longitudinal, diversified, didactic or practical HDSE. This appeared to be caused by systemic- and participant-level barriers including a lack of opportunities for HDSE. It is possible that hospitals/practice systems lack the specialization and expertise needed to build lasting training structures, the resources to outsource training, the capacity to prioritize training for all physicians, or the knowledge that there is an unmet need. ${ }^{3,27,28}$ For those physicians who had received HDSE, education was limited to periodic singleday conference-style opportunities and on-the-jobtraining in specific topics related to administrative needs. While this approach (termed "scatter-shot") is popular and possibly effective in the short term, it is unlikely to create the scale and sustainability in physician leadership needed to champion the systemic change participants desired. ${ }^{3}$

Time and cost were the limitations that kept most physicians from pursuing HDSE. Low-cost or free online learning platforms (webinars, longitudinal distancelearning certificate programs done in short segments) are potential solutions. $^{29}$ The steady rise of certificates, CME electives, and non-masters level opportunities for physicians over the last decade shows a promising trend in reducing participant barriers. ${ }^{30,31}$ However, it is likely 
Table 3 Perceptions of the Certificate Program: An Outline Utilizing the Diffusion of Innovation Theory

\begin{tabular}{|c|c|c|}
\hline $\begin{array}{l}\text { Participant-Perceived } \\
\text { Attributes of the } \\
\text { Certificate Program }\end{array}$ & Description of Attribute & $\begin{array}{l}\text { Participants' Viewpoints Related to Each Attribute of } \\
\text { the Certificate Program }\end{array}$ \\
\hline Relative advantage & $\begin{array}{l}\text { Participant perceived the certificate was beneficial } \\
\text { to them and added to their existing skillset }\end{array}$ & $\begin{array}{l}\text { Participants stated they were deficient in healthcare delivery } \\
\text { science education and wanted more. They valued the HDSE } \\
\text { knowledge provided by the certificate because it would allow } \\
\text { them to improve their practice and help their patient } \\
\text { population. Participants valued the certificate for solving } \\
\text { management/efficiency problems at their place of work with } \\
\text { their co-workers and for improving their own perceived } \\
\text { limitations. Participants valued the certificate's ability to } \\
\text { provide them skills to advocate for their patients on topics, } \\
\text { such as mental health reform, and to complete projects that } \\
\text { directly investigated/improve issues facing their patient } \\
\text { populations. }\end{array}$ \\
\hline Compatibility & $\begin{array}{l}\text { Participant perceived the certificate program was } \\
\text { coherent with their existing environment and their } \\
\text { needs }\end{array}$ & $\begin{array}{l}\text { Participants saw value in the expert lecturers, discussions } \\
\text { with their peers, and online learning. They stated they } \\
\text { thought the time requirements and length of the program } \\
\text { were reasonable. The project component was congruent } \\
\text { with physician needs if there was flexibility in completion } \\
\text { dates over the three years, if it was specific to their specialty, } \\
\text { and if they were not retiring. }\end{array}$ \\
\hline Complexity & $\begin{array}{l}\text { Participant perceived the innovation was difficult to } \\
\text { complete }\end{array}$ & $\begin{array}{l}\text { Participants reported that the certificate program would help } \\
\text { them understand aspects of healthcare delivery science, } \\
\text { which they perceived to be difficult to learn on their own. } \\
\text { They thought the certificate was manageable and no one } \\
\text { stated it was too many hours or too burdensome in length. }\end{array}$ \\
\hline Trialability & $\begin{array}{l}\text { Participant perceived the certificate program was } \\
\text { accessible for trial without total dedication and } \\
\text { with minimal investment }\end{array}$ & $\begin{array}{l}\text { When participants were asked if they wanted more of an } \\
\text { opportunity to try the course before joining or less of an } \\
\text { opportunity (with a formal application and required time } \\
\text { comment) they were happy with the program as is. }\end{array}$ \\
\hline Observability & $\begin{array}{l}\text { Participant was ability to envision the benefits of } \\
\text { the certificate program }\end{array}$ & $\begin{array}{l}\text { Participants listed many applications, research projects, } \\
\text { quality improvement projects, advocacy goals, and policy } \\
\text { ambitions they could accomplish with the HDSE knowledge } \\
\text { gained through the certificate. They also envisioned social } \\
\text { benefits of learning with/meeting like-minded people and } \\
\text { involving their existing co-workers in new HDSE projects. }\end{array}$ \\
\hline
\end{tabular}

that the time constraints of practicing physicians will continue to force many physicians to rely on the HDSE they received in medical school and residency training. ${ }^{32,33}$ Consequently, the medical education system should prioritize important HDSE topics and integrate them into the existing accreditation and education requirements. ${ }^{28,32,33}$

The main motivations physicians reported for pursuing HDSE were their desire to improve an aspect of their healthcare system or practice, and their desire to help their patient populations. This finding suggests many physicians saw a direct application for HDSE. Physicians interviewed were largely dissatisfied with policies and operations and lacked the skillsets to institute or advocate for a change. Concern for this was the prime motivation for our study. We are not surprised physicians were motivated by their desire to improve work conditions, environments, and policies. Three of the four factors that Linzer and others identified as causing burnout in healthcare professions include an inability to change work conditions, an inefficient work environment, and a misalignment of 
values and missions between physicians and the hierarchical executives or system. ${ }^{34-37}$ As physicians continue to perceive that changes need to be made and they are increasingly managed with standardized algorithms, workflows, and reimbursement policies, it is likely the motivations for the skillsets to change these will have more importance.

Physicians in our study were interested in the proposed limited model of the longitudinal HDSE certificate program because it allowed for didactic expert-led education, mentoring of future physicians, and networking with their peers. During interviews, physicians expressed an interest in applying the example certificate program's project requirement to develop independent and collaborative efforts to solve the various access and management issues facing their practices and hospital systems. This could indicate physicians perceived their colleagues needed HDSE applied skillsets as well, or that they believe there are needed projects that require the work and commitment of a team. Either way, it is important future HDSE programs teach applied skills as well as didactic knowledge. ${ }^{27,38}$

\section{Strengths and Limitations}

Recall bias is a possible limitation among physicians remembering their educational experiences. However, we utilized signposting between each section and probing after each question to help physicians formulate their best answers. Member checking was not conducted. Interviewer bias was mitigated through recorded interviews and multiple coders. Interviewee reporting bias was mitigated by the ability to opt out of questions, and reassurance of data safety measures and de-identification.

We used a sample size similar to other articles with similar study designs, as well as an established saturation approach in our analysis. ${ }^{39-41}$ The physicians in this study originated from a single rural state and were chosen from two different sources using purposeful convenience sampling. Thus, the themes generated in this study may not be representative of the viewpoint of all physician populations nor generalizable to other populations. However, the goal of this study and qualitative research is not to generalize results, but to gain a deeper, non-numerical understanding of a culture. ${ }^{42}$ Qualitative studies analyze subjects' experiences and thoughts in order to attain an insider's view of the group under study. ${ }^{42}$ The information and insights related to the culture experienced by this group of practicing physicians can inform other researchers of potential cultures in their own study populations, and encourage further qualitative studies of other physician populations, generalizable quantitative studies of larger physician populations, and intervention studies to meet the HDSE needs of specific physician groups.

Qualitative studies that assess differences in viewpoints between other strata, such as gender, rurality of practice, fellowship training, rurality of patient population, and prior training experience are needed. This study was of physicians in a rural state. These physicians may have had low access to academic medical centers for continual training and education, high probability of working at a small practice and/or hospital, more difficulty recruiting and retaining peers with leadership expertise, more patients with government insurance or uninsured status, and higher likelihoods of working in settings owned by a healthcare system due to the limited viability of the rural independent practice. Further studies are needed with comparisons across rurality and within urban states.

\section{Conclusion}

The physicians in our qualitative study were interested in obtaining HDSE and had not received diversified, didactic HDSE in the past. Thus, there is a need for HDSE and the best time for the training is likely to be in the early stages of medical careers or during medical training. Development of further HDSE opportunities could provide physicians with the skills needed to make changes to their work environments and policies, enable them to help their patient populations, and increase their successes when participating in informal and formal leadership and management roles. Our research suggests innovative HDSE programs will likely be utilized and pursued if they are developed. Further research is needed in other physician populations' HDSE culture and experiences.

\section{Acknowledgments}

We would like to thank Telligen Community Initiative, the Iowa Research Network (IRENE), the University of Iowa Surgery Department, Hugh Hansen, Clay Walker, Hayley Hansen, Katherine Merritt, Usha Balakrishnan, Diane Berwald, Jaclyn Searls, Kelli Parsons, Savannah Borman, and Heather Healy.

\section{Author Contributions}

All authors made a significant contribution to the work reported, whether that is in the conception, study design, execution, acquisition of data, analysis and interpretation, or in all these areas; took part in drafting, revising or critically reviewing the article; gave final approval of the 
version to be published; have agreed on the journal to which the article has been submitted; and agree to be accountable for all aspects of the work.

\section{Funding}

A grant from Telligen Community Initiative obtained by the student leadership board of the Healthcare Delivery Science, Management, and Policy Distinction track at the University of Iowa funded this study. No one on the research team received a direct payment or increase in salary from Telligen Community Initiative for conducting this study.

\section{Disclosure}

The authors report no conflicts of interest in this work.

\section{References}

1. Chaudry J, Jain A, McKenzie S, Schwartz RW. Physician leadership: the competencies of change. J Surg Educ. 2008;65(3):213-220. doi:10.1016/j.jsurg.2007.11.014

2. Sonnino RE. Health care leadership development and training: progress and pitfalls. J Healthc Leadersh. 2016;8:19-29. doi:10.2147/ JHL.S68068

3. Myers CG, Pronovost PJ. Making management skills a core component of medical education. Acad Med. 2017;92(5):582-584. doi:10.1097/ACM.0000000000001627

4. Centers for Medicare \& Medicaid Services. National Health Expenditures 2017 Highlights. Centers for Medicare \& Medicaid Services; 2019.

5. Silbaugh BR, Leider HL. Physician leadership is key to creating a safer, more reliable health care system. Physician Exec. 2009;35 (5):12-16.

6. Faerber A, Andrews A, Lobb A, et al. A new model of online health care delivery science education for mid-career health care professionals. Healthc. 2019;7(4). doi:10.1016/j.hjdsi.2018.12.002.

7. Pearl RM, Fogel AL. New physicians will need business school skills. NEJM Catalyst. 2017;3(4).

8. Goodall AH. Physician-leaders and hospital performance: is there an association? Soc Sci Med. 2011;73(4):535-539. doi:10.1016/j. socscimed.2011.06.025

9. Castro PJ, Dorgan SJ, Richardson B. A healthier health care system for the United Kingdom. McKinsey Q. 2008;1-5.

10. Mountford J, Webb C. When clinicians lead: the McKinsey Quarterly. Healthc Leadersh Rep. 2009;28(5):1-3.

11. Falcone RE, Satiani B. Physician as hospital chief executive officer. Vasc Endovascular Surg. 2008;42(1):88-94. doi:10.1177/1538574407309320

12. Tasi MC, Keswani A, Bozic KJ. Does physician leadership affect hospital quality, operational efficiency, and financial performance? Health Care Manage Rev. 2019;44(3):3. doi:10.1097/HMR.0000000000000173

13. Hartley K. Untangling approaches to management and leadership across systems of medical education. BMC Health Serv Res. 2016;16(2):33-43. doi:10.1186/s12913-016-1391-9

14. Patel MS, Davis MM, Lypson ML. Advancing medical education by teaching health policy. $N$ Engl J Med. 2011;364(8):695-697. doi:10.1056/NEJMp1009202

15. Gonzalo JD, Dekhtyar M, Starr SR, et al. Health systems science curricula in undergraduate medical education: identifying and defining a potential curricular framework. Acad Med. 2017;92(1):123-131. doi:10.1097/ACM.0000000000001177
16. DeFlitch C, Geeting G, Paz HL. Reinventing emergency department flow via healthcare delivery science. HERD. 2015;8(3):105-115. doi:10.1177/1937586715580949

17. Starr SR, Reed DA, Essary A, et al. Science of health care delivery as a first step to advance undergraduate medical education: a multi-institutional collaboration. Healthcare. 2017;5(3):98-104. doi:10.1016/j.hjdsi.2017.01.003

18. Gupta A, Sharda R. Improving the science of healthcare delivery and informatics using modeling approaches. Decis Support Syst. 2013;55 (2):423-427. doi:10.1016/j.dss.2012.10.001

19. Shipman SA, Wendling A, Jones KC, Kovar-Gough I, Orlowski JM, Phillips J. The decline in rural medical students: a growing gap in geographic diversity threatens the rural physician workforce. Health Aff. 2019;38(12):2011-2018. doi:10.1377/hlthaff.2019.00924

20. Probst J, Eberth JM, Crouch E. Structural urbanism contributes to poorer health outcomes for rural America. Health Aff. 2019;38 (12):1976-1984. doi:10.1377/hlthaff.2019.00914

21. Polit DF, Beck CT. Generalization in quantitative and qualitative research: myths and strategies. Int $J$ Nurs Stud. 2010;47 (11):1451-1458. doi:10.1016/j.jijurstu.2010.06.004

22. Moseley SF. Everett Rogers' diffusion of innovations theory: its utility and value in public health. J Health Commun. 2004;9 (S1):149-151. doi:10.1080/10810730490271601

23. Rogers EM. Diffusion of Innovations. Simon and Schuster; 2010.

24. Guest G, Bunce A, Johnson L. How many interviews are enough? An experiment with data saturation and variability. Field Methods. 2006;18(1):59-82. doi:10.1177/1525822X05279903

25. Luborsky MR. The Identification and Analysis of Themes and Patterns. 1994.

26. Rodriguez JG. Commentary: grounded theory and the constant comparative method. Br Med J. 1998;316(7137):1064-1066.

27. Butterworth K, Hayes B, Zimmerman M. Remote and rural: do mentors enhance the value of distance learning continuing medical education? Educ Health. 2011;24(3):539.

28. Goodall A, Stoller JK. The future of clinical leadership: evidence for physician leadership and the educational pathway for new leaders. BMJ Leader. 2017;1(2):8. doi:10.1136/leader-2017-000010

29. Atreja A, Mehta NB, Jain AK, et al. Satisfaction with web-based training in an integrated healthcare delivery network: do age, education, computer skills and attitudes matter? BMC Med Educ. 2008;8 (1):48. doi:10.1186/1472-6920-8-48

30. Herzlinger RE, Kumar V, Schulman K, Staman K. Innovation in Health Care Education: A Call to Action. 2015.

31. Rotenstein L, Perez K, Wohler D, et al. Preparing health professions students to lead change. Leadersh Health Serv. 2019;32(2):182-194. doi:10.1108/LHS-02-2018-0011

32. Bohmer RM. Managing the new primary care: the new skills that will be needed. Health Aff. 2010;29(5):1010-1014. doi:10.1377/hlthaff. 2010.0197

33. Emanuel EJ. Changing premed requirements and the medical curriculum. JAMA. 2006;296(9):1128-1131. doi:10.1001/jama.296.9.1128

34. Rothenberger DA. Physician burnout and well-being: a systematic review and framework for action. Dis Colon Rectum. 2017;60 (6):567-576. doi:10.1097/DCR.0000000000000844

35. Linzer M, Manwell LB, Williams ES, et al. Working conditions in primary care: physician reactions and care quality. Ann Intern Med. 2009;151(1):28-36, w26-29. doi:10.7326/0003-4819-151-1-2009070 70-00006

36. Linzer M, Konrad TR, Douglas J, et al. Managed care, time pressure, and physician job satisfaction: results from the physician worklife study. J Gen Intern Med. 2000;15(7):441-450. doi:10.1046/j.15251497.2000.05239.x

37. Linzer M, Visser MR, Oort FJ, Smets EM, McMurray JE, de Haes HC. Predicting and preventing physician burnout: results from the United States and the Netherlands. Am J Med. 2001;111 (2):170-175. doi:10.1016/S0002-9343(01)00814-2 
38. Nelson EA, McGuire AL. The need for medical education reform: genomics and the changing nature of health information. Genome Med. 2010;2(3):18. doi:10.1186/gm139

39. Saunders B, Sim J, Kingstone T, et al. Saturation in qualitative research: exploring its conceptualization and operationalization. Qual Quant. 2018;52(4):1893-1907. doi:10.1007/s11135-0170574-8
40. Boddy CR. Sample size for qualitative research. Qual Market Res Int J. 2016;19(4):426-432. doi:10.1108/QMR-06-2016-0053

41. Charmaz K, Belgrave L. Qualitative interviewing and grounded theory analysis. SAGE Handb Interview Res. 2012;2:347-365.

42. Tuli F. The basis of distinction between qualitative and quantitative research in social science: reflection on ontological, epistemological and methodological perspectives. Ethiop J Educ Sci. 2010;6(1).

\section{Publish your work in this journal}

Advances in Medical Education and Practice is an international, peerreviewed, open access journal that aims to present and publish research on Medical Education covering medical, dental, nursing and allied health care professional education. The journal covers undergraduate education, postgraduate training and continuing medical education including emerging trends and innovative models linking education, research, and health care services. The manuscript management system is completely online and includes a very quick and fair peer-review system. Visit http://www.dovepress.com/testimonials.php to read real quotes from published authors. 